\title{
Spatio-temporal variations in photosynthesis
}

\author{
Ichiro Terashima $^{1} \cdot$ Yanhong Tang $^{2} \cdot$ Hiroyuki Muraoka ${ }^{3}$
}

Published online: 4 April 2016

(C) The Botanical Society of Japan and Springer Japan 2016

In this JPR symposium, we compile articles that examine responses of photosynthesis to spatio-temporal variations of the light environment. One feature is the scaling with respect to the sizes of photosynthetic systems. Biochemistry at the chloroplast level, light environment within a leaf, development and senescence of leaf photosynthesis within tree individuals and nitrogen distribution in leaf canopies are argued. The other is the time scale. Fluctuations of environmental variables at the orders of sub-seconds to minutes, photosynthesis induction in sunflecks, and annual changes in the leaf photosynthetic traits and effects of the sowing period on interspecific competition are focused. Currently, photosynthesis is approached at various scales, ranging from structural biology at the atomic scale to the global scale ecology using the Earth observation satellites. Although there were several large and deep gaps between the scales, scientists have been trying to fill these gaps. In such the scaling approaches encompassing various scales, the theory developed by Monsi and Saeki (1953) is widely regarded as a vital milestone. The original paper by Monsi and Saeki was written in German, but the English version, translated by Schortemeyer, is now available (Monsi and Saeki 2005). The success of the Monsi-Saeki theory is that the light environment within a leaf canopy is expressed

Ichiro Terashima

itera@bs.s.u-tokyo.ac.jp

1 Department of Biological Sciences, School of Science, The University of Tokyo, 7-3-1 Hongo, Bunkyo-ku, Tokyo 113-0033, Japan

2 Center for Environmental Biology and Ecosystem Studies, National Institute for Environmental Studies, Onogawa 16-2, Tsukuba 305-0053, Japan

3 River Basin Research Center, Gifu University, 1-1 Yanagido, Gifu 501-1193, Japan by one very simple Beer-Lambert equation with only two parameters, the leaf area index, $F$ (or LAI), and the absorption coefficient, $k . F$ is defined as the cumulative leaf area from the canopy top to an arbitrary plane in the canopy divided by the ground area. This plane can be the ground surface; $F$ thus obtained for all the leaves in the canopy, $F_{\text {tot }}$, is a parameter representing the leaf canopy. $k$ is a constant related to leaf inclination and is also important for characterizing the leaf canopy as is briefly explained below. For historical overviews of the research field before and after the Monsi-Saeki theory, see Monsi et al. (1973) and Hirose (2005).

The success of the Monsi-Saeki relies on their simple assumptions. They treated as a leaf canopy as an assembly of small leaves that have the identical inclinations and are distributed randomly in the canopy. Let us assume that each of the leaves in such a canopy has an area of $s$ and is horizontal and above the ground area of $S$. Then, the average light intensity below the top leaf, $I_{1}$, in the canopy can be expressed as

$I_{1}=I_{0} \frac{S-s}{S}$,

where $I_{0}$ is the light intensity measured above the canopy. Because the top leaf is horizontal, its shadow on the plane just below the top leaf is $s$. Similarly, the average light intensity below the nth leaf from the top can be expressed as

$I_{\mathrm{n}}=I_{0}\left(\frac{S-s}{S}\right)^{n}$.

Then, logarithm of both sides yields;

$\ln I_{\mathrm{n}}=\ln I_{0}+n \ln \left(1-\frac{s}{S}\right)$. 
Because $s \ll S$, we can use the approximation. Then, $\ln$ $I_{\mathrm{n}}$ is expressed as

$\ln I_{\mathrm{n}} \approx \ln I_{0}-\frac{n s}{S}$.

Let the leaf area index from the canopy top to the plane just below the nth leaf be $F$. Then, the light intensity at this plane, $I_{\mathrm{F}}$, can be expressed as

$I_{\mathrm{F}} \approx I_{0} e^{-F}$.

when the leaves are inclined, the 'average' area of the leaf shadow is smaller than $s$. Let us express the 'average' shadow area $k s$. Then, the light intensity at $F$ can be expressed as

$I_{\mathrm{F}} \approx I_{0} e^{-k F}$.

Monsi and Saeki (1953) expressed $k$ with complicated trigonometric equations.

Light absorption by the leaf at $F, A_{\mathrm{F}}$, can be calculated assuming that the decrease in the light intensity from $F$ to $F+\Delta F$ is attributed to the light absorption by $\Delta F$. Because the equation is the definition of the derivative of the function $I_{0} e^{-k F}$ with the - sign, $A_{\mathrm{F}}$ can be calculated as

$$
\begin{aligned}
A_{\mathrm{F}} & =\lim _{\Delta F \rightarrow 0} \frac{I_{0} e^{-k F}-I_{0} e^{-k(F+\Delta F)}}{\Delta F} \\
& =-\lim _{\Delta F \rightarrow 0} \frac{I_{0} e^{-k(F+\Delta F)}-I_{0} e^{-k F}}{\Delta F}=k I_{0} e^{-k F} .
\end{aligned}
$$

Then, it is possible to calculate the rate of photosynthesis at any position within the canopy. Integration of the rate of photosynthesis with respect to $F_{\text {tot }}$ is photosynthesis of the canopy. In this simple calculation, we assume that the transmittance of the leaf is 0 . We easily incorporate the leaf transmittance $T$;

$I_{\mathrm{F}}=I_{0} e^{-(1-T) k F}$.

From the above, it may be clear that $k$, defined as the 'average shade area,' for the direct sunbeam and that for diffuse light from the sky would be different. Although recent models of canopy photosynthesis adopt the binary (sunlit or shaded) model developed by de Pury and Farquhar (1997), we may be able to reconsider incorporation of an up-dated version of the Monsi and Saeki (1953) multilayered model incorporating two extinction coefficients for direct light and diffuse light $k_{\mathrm{dir}}$ and $k_{\mathrm{dif}}$. Recently, Hikosaka (2014) developed a theory that can accommodate the direct-diffuse light problem with the multi-layered model using $k$ ' for diffuse light and expressing the decay of the fraction of the leaves exposed to direct light with $F$ as $e^{-k^{\prime} s}$. Hikosaka (2016) reviewed the papers concerning the optimality of nitrogen partitioning among leaves in plant canopies, including the problems of the diffuse-direct light.
Because the optimum nitrogen partitioning should be considered in relation to fitness of the individual plants rather than the stand consisting of many individuals, the approach using the game theory is also highlighted.

Leaves develop, photosynthesize and senesce in the leaf canopy. Thus, these processes are all affected by the light gradient in the canopy. Moreover, expansion of the leaves itself changes the light gradient. Namely, the light gradient differs depending on the position within the canopy and with time in terms of leaf development and senescence. Comprehensive understanding of these processes may be the most difficult N-body problem in this research field. Niinemets (2016) tackled this problem bravely to find out trends in the complicated situations by meta-analyzing the relevant papers, most of which only fragmentally related to the problem.

Iwaki (1959), one of the students of Monsi applied the Monsi and Saeki approach to analyze an interspecific competition. Oikawa who is also a Monsi's student, introduced the Monte Carlo method to calculate the light extinction in the plant canopy (Oikawa and Saeki 1977). In this JPR SYMPOSIUM, Evers and Bastiaans (2016) developed a state of the art interspecific competition model between the weed and crop species using these two approaches. Effects of the crop spatial arrangement and the sowing date on weed suppression were analyzed using this functionalstructural plant modelling.

A leaf can be regarded as a micro-analogue of a leaf canopy as claimed by Shul'gin et al. (1978). Then, each chloroplast in the leaf corresponds a single leaf in the canopy. There is certainly a steep gradient of light environment in a single leaf. However, the nature of the light gradient within a leaf differs from that in the leaf canopy. At least for the photosynthetically active radiation, the green leaf can be regarded as a rather translucent material for the first approximation. On the other hand, chloroplasts in the leaf cannot be assumed to be translucent even for the first approximation. Several groups have been working on the light environment within the leaf. Terashima et al. (2016) in this JPR SYMPOSIUM reviewed the results from these laboratories for the last one-third century or so, mainly focusing on the roles of blue and red light and green light. Also the roles of the palisade and spongy tissues are discussed. Since the PAM fluorometer was commercially available in 1980 s, there have been numerous studies using the PAM system (Schreiber 2004). However, it should be noted that the fluorescence signals obtained with the PAM systems may not represent the photosynthetic status of the whole leaf. It is effective to use blue measuring beam preferentially exciting PSII to minimize the contamination of fluorescence from PSI (Pfündel 1998), but, the blue measuring beam just excites the chloroplasts located near the illuminated surface and thus the 
fluorescence signals detect what occur in the surface chloroplast. Such technical problems are also argued (see also Oguchi et al. 2011).

Since the series of studies made by Pearcy and his associates, photosynthesis in sunflecks has been attracting attention of ecophysiologists (Pearcy 1990, Pearcy and Way 2012). Tomimatsu and Tang (2016) reviewed the recent studies examining effects of high $\mathrm{CO}_{2}$ concentration in air on the induction of photosynthesis upon illumination and post-illumination $\mathrm{CO}_{2}$ fixation. Effects of instantaneous elevation of $\mathrm{CO}_{2}$ concentration and those of growth in high $\mathrm{CO}_{2}$ air are separately argued. It is necessary to incorporate these effects to predict photosynthetic production in the coming high $\mathrm{CO}_{2}$ era. Also the analyses are important for improving photosynthetic production by breeding.

Yamori (2016) reviewed effects of fluctuating environments including the fluctuating light on leaf photosynthesis. This article also includes original data of fluctuating environmental variables such as temperature, humidity, and $\mathrm{CO}_{2}$ concentration in seedlings of Oryza sativa. All these fluctuating variables except for the fluctuating light induced photoinhibition of photosystem II (PS II), while the fluctuating light gave damage to PS I. Factors that potentially responsible for these damages are extensively argued. This review part of Yamori's article give overviews of what would happen in chloroplasts in fluctuating environments.

The articles in this JPR SYMPOSIUM are chosen from the talks given at the annual meeting of the Botanical Society of Japan held in September 2014. There were talks devoted for the electron transport systems in the chloroplasts and for the annual changes in the photosynthetic production in a deciduous forest. For the roles of cyclic electron transport around PSI in protecting PSI photoinhibition in the fluctuating light, the readers may refer to recent papers and reviews (Soursa et al. 2012, Kono et al. 2014, Kono and Terashima 2014, Allahverdiyeva et al. 2015). The readers who are interested in the studies at the forest ecosystem level including the satellite ecology, refer to recent reviews (Muraoka and Koizumi 2009, Muraoka et al. 2010, Chung et al. 2013, Noda et al. 2014, Ruidish et al. 2014) which can be found in a joint virtual special issue by Journal of Plant Research and Ecological Research 'Long-term and multidisciplinary research of the forest carbon cycle at the Takayama site, Japan (http://www.springer. com/life+sciences/plant+sciences/journal/10265)'.

\footnotetext{
Acknowledgments Journal of Plant Research is sponsoring one International Symposium at every annual meeting of the Botanical Society of Japan. We are grateful to the Society, especially Professor Ikuo Nishida, the editor-in-chief of Journal of Plant Research, for their cordial support, which enabled us to invite Professor Ülo Niinemets and Dr. Jochem B. Evers to our symposium and publish our articles in this JPR SYMPOSIUM.
}

\section{References}

Allahverdiyeva Y, Suorsa M, Tikkanen M, Aro E-M (2015) Photoprotection of photosystems in fluctuating light intensities. J Exp Bot 66:2427-2436. doi:10.1093/jxb/eru463

Chung H, Muraoka H, Nakamura M, Han S, Muller O, Son Y (2013) Experimental warming studies on tree species and forest ecosystems: a literature review. J Plant Res 126:447-460. doi:10.1007/ s10265-013-0565-3

de Pury DGG, Farquhar GD (1997) Simple scaling of photosynthesis from leaves to canopies without the errors of big-leaf models. Plant, Cell Environ 20:537-557. doi:10.1111/j.1365-3040.1997.00094.x

Evers JB, Bastiaans L (2016) Quantifying the effect of crop spatial arrangement on weed suppression using functional-structural plant modelling. J Plant Res 1239 (in press)

Hikosaka K (2014) Optimal nitrogen distribution within a leaf canopy under direct and diffuse light. Plant, Cell Environ 37:2077-2085. doi:10.1111/pce.12291

Hikosaka K (2016) Optimality of nitrogen partitioning among leaves in plant canopies. J Plant Res 1239 (in press)

Hirose T (2005) Development of the Monsi-Saeki theory on canopy structure and function. Ann Bot 95:483-494. doi:10.1093/aob/ mci047

Iwaki H (1959) Ecological studies on interspecific competition in a plant community. I. An analysis of growth of competing plants in mixed stands of buckwheat and green gams. Jpn J Bot 17:120-138

Kono M, Terashima (2014) Long-term and short-term responses of the photosynthetic electron transport to fluctuating light. J Photochem Photobiol, B 137:89-99. doi:10.1016/j. jphotobiol.2014.02.016

Kono M, Noguchi K, Terashima (2014) Roles of the cyclic electron flow around PSI (CEF-PSI) and $\mathrm{O}_{2}$-dependent alternative pathways in regulation of the photosynthetic electron flow in shortterm fluctuating light in Arabidopsis thaliana. Plant Cell Physiol 55:990-1004. doi:10.1093/pcp/pcu033

Monsi M, Saeki T (1953) Über den Lichtfaktor in den Pflanzengesellschaften und seine Bedeutung für die Stoffproduktion der Pflanzen. Jpn J Bot 14:22-52

Monsi M, Saeki T (2005) On the factor light in plant communities and its importance for matter production. Ann Bot 95:549567. doi:10.1093/aob/mci052 (Translated by Dr. MARCUS SCHORTEMEYER)

Monsi M, Uchijima Z, Oikawa T (1973) Structure of foliage canopies and photosynthesis. Annu Rev Ecol Syst 4:301-327

Muraoka H, Koizumi H (2009) Satellite ecology (SAECO)-linking ecology, remote sensing and micrometeorology, from plot to regional scale, for the study of ecosystem structure and function. J Plant Res 122:3-20. doi:10.1007/s10265-008-0188-2

Muraoka H, Saigusa N, Nasahara KN et al (2010) Effects of seasonal and interannual variations in leaf photosynthesis and canopy leaf area index on gross primary production of a cool-temperate deciduous broadleaf forest in Takayama, Japan. J Plant Res 123:563-576. doi:10.1007/s10265-009-0270-4

Niinemets Ü (2016) Leaf age dependent changes in within-canopy variation in leaf functional traits: a meta-analysis. J Plant Res 1239 (in press)

Noda HM, Muraoka H, Nasahara KM, Saigusa N, Murayama S, Koizumi H (2014) Phenology of leaf morphological, photosynthetic, and nitrogen use characteristics of canopy trees in a cool-temperate deciduous broadleaf forest at Ta-kayama, central Japan. Ecol Res. doi:10.1007/s11284-014-1222-6

Oguchi R, Terashima I, Kou J, Chow WS (2011) Operation of dual mechanisms that both lead to photoinactivation of 
Photosystem II in leaves by visible light. Physiol Plant 142:4755. doi:10.1111/j.1399-3054.2011.01452.x

Oikawa T, Saeki T (1977) Light regime in relation to plant population geometry I. A Monte Carlo simulation of light microclimte within a random distribution foliage. Bot Mag Tokyo 90:1-10

Pearcy RW (1990) Sunflecks and photosynthesis in plant caopies. Annu Rev Plant Physiol Plant Mol Biol 41:421-453. doi:10.1146/annurev.pp.41.060190.002225

Pearcy RW, Way DA (2012) Two decades of sunfleck research: looking back to move toward. Tree Physiol 32:1059-1061. doi:10.1093/treephys/tps084

Pfündel E (1998) Estimating the contribution of photosystem I to total leaf chlorophyll fluorescence. Photosynth Res 56:185-195. doi:1 0.1023/A:1006032804606

Ruidisch M, Nguyen TT, Li Y, Geyer R, Tenhunen J (2014) Estimation of annual spatial variations in forest production and crop yields at landscape scale in temperate climate regions. Ecol Res. doi:10.1007/s11284-014-1208-4

Schreiber U (2004) Pulse-amplitde-modulation (PAM) fluorometry and saturation pulse method: an overview. In: Papageorgiou GC, Govindjee (eds) Chlorophyll $a$ fluorescence; a signature of photosynthesis. Springer, Dordrecht, pp 279-319 (ISBN 978-1-4020-3217-2)

Shul'gin IA, Murei IA, Nichiporovich AA (1978) Structuro-functional organization of the leaf as an integral photosynthesizing system. Fiziol Ras 25:76-85 (Sov Plant Physiol 25: 55-62)

Suorsa M, Järvi S, Grieco M, Nurmi M, Pietrzykowska M, Rantala M, Kangasjärvi S, Paakkarinen V, Tikkanen M, Jansson S, Aro EM (2012) PROTON GRADIENT REGULATION 5 is essential for proper Acclimation of Arabidopsis photosystem I to naturally and artificially fluctuating light conditions. Plant Cell 24:29342948. doi:10.1105/tpc.112.097162

Terashima I, Ooeda H, Fujita T, Oguchi (2016) Light environment within a leaf. II. Progress in the past one third century. J Plant Res 1239 (in press)

Tomimatsu H, Tang Y (2016) High $\mathrm{CO}_{2}$ effects on dynamic photosynthesis: carbon gain, mechanisms and environmental interactions. J Plant Res 1239 (in press)

Yamori W (2016) Photosynthetic response to fluctuating environments and photoprotective strategies under abiotic stress. J Plant Res 1239 (in press) 